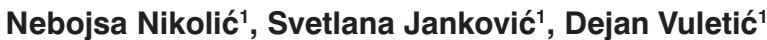
${ }^{1}$ Strategic Research Institute, Ministry of Defence, Republic of Serbia,

UDC: 005.52:005.33 005.583.1:355

\title{
Interdepartmental Cooperation in Defence Issues and Strategic Intelligence
}

DOI: 10.7595/management.fon.2016.0017

\begin{abstract}
The motivation for this paper comes from one successfully conducted empirical research about motivation of potential candidates to serve in the active reserve as a kind of military service which is recently introduced in the Serbian Army. The research team was faced with a set of problems related to the deadlines, resources and mandate issues. A solution was found in agile interdepartmental cooperation. Firstly, we started with identification of missing resources and mandates of our research team. Then, we investigated where we could find the missing issues. After that, we established lines for cooperation with other departments in the MoD. The clarity of interdepartmental communication and concretisation of demands and expectations were crucial for success. In the end we realized the full potential of interdepartmental cooperation and started to think about that phenomenon in the wider context of defence and security issues. We found some other examples of interdepartmental cooperation in earlier efforts of the defence sector reform, as well as some results in other armies. The paper presents strengths and opportunities of interdepartmental cooperation through temporary engaged working groups in the specific defence sector environment, as well as potential obstacles. In a wider aspect, interdepartmental cooperation in defence and security issues becomes more and more important because of new security challenges we are facing today.
\end{abstract}

Keywords: military active reserve, recruitment, interdepartmental working groups, decision making, strategic intelligence, SWOT.

\section{Introduction}

Interdepartmental, inter-organizational and more general interagency working groups are a relatively new and growing phenomenon, particularly in the public domain. They appear as an answer to new challenges and demands imposed as regards the existing organizational structures. The need for interdepartmental and interagency joint endeavour emerged in specific cases related to the un-ordinary, occasionally, and usually complex tasks that they have to perform. In such cases, resource, knowledge or even authorization of a single entity are not enough. Hence, different organizations have to work together: exchange information, share resources, coordinate actions, and, in general, behave in a cooperative manner. However, different departments in a single large organization also have their internal relationship dynamics. In case of organizations with complex structures, more departments, interfering functions, formalized organizational behaviour, rigid communication procedures, administrative and decision making bottlenecks, there are many opportunities for improvement. This is particularly the case with public service organizations.

On the other hand (other then public administration), in the field of business relationships and industrial markets, there is a reliable history of awareness of the "network perspective" and comprehension that actors do not operate in isolation (Hakansson and Snehota, 1995). Efforts to improve organizational design of commercial companies are permanent and long-term. Research studies on organizational design discussed issues about functional and project forms (Galbraith, 1971) and proposed matrix organizational design. Miles and Snow (1986) pointed out the "dynamic network" as a new organizational form invented to respond to declining productivity and competitive requirements. They further developed the "dynamic network" concept and discussed it in the wider context of networks typology (Snow and Miles, 1992). The next step in the 
development of network organization was the concept of a "spherically structured firm" (Miles and Snow, 1995), a kind of multi-firm network which is based on a set of the following principles: mutual independence, preference, non-competition and non-exploitation; flexibility and business autonomy; network democracy; expulsion; subcontracting limitless; entry openness; and exit freedom (Miles and Snow, 1995). The "Network paradigm" became more important in the environment of globalisation process, and elevated network related research efforts very high as noted by Borgatti and Foster (2003). A dynamic aspect of the company's capabilities, combined with two crucial relations of networked organizations (cooperation and competition), were recently elaborated through the experience of a famous global company (Song et al., 2016).

Different issues have been taken into consideration both on "Network paradigm" and in an environment of small transitional societies and their economies: Čudanov et al. (2009) have investigated the influence of IC technologies (Information and Communication) on the decentralization of the organizational structure. They made in-depth research of more than seventy companies in Serbia, and found out that: "decentralization is not a discrete but a continual process, and authority migrates slowly to organizational units where information is concentrated" (Čudanov et al., 2009). Also, they found that a way of using IC technologies and consequently created opportunities make the difference but not technology itself. Organizational networks, and particularly efficiency aspect, were subject of research preformed by Jaško et al., (2010), where they pointed out that the combination of analytical network and management perspective are crucial for the management of the efficiency of organizational networks. Petković et al., (2014) used organizational network analysis in order to describe factors of influence for designing a learning network organization. Petković and Aleksić-Mirić (2009) analysed the managing organizational knowledge in a process of downsizing. The last two works could be of particular interest for researchers and managers in the military and defence sectors, due to an almost constant process of transformation and reform, as well as a well known premise that the military, when it is not in its primary mission, always learns and conducts training and exercise.

There is an increasing practice of establishing interdepartmental and interagency working groups on a temporal basis, particularly in large and complex public organizations. Reasons for that can be various. Sometimes it is because of the needs for comprehensive organizational changes which are initiated from the top political level from time to time. Sometimes the reason is the need to unify efforts and resources for efficient supporting of an important, complex, temporary and usually unique task, such as: emergency situations, large scale public events (sports events, international conferences, music festivals, etc.) and similar occasions. In case of this work, the initial reason was a declared need by the top level decision maker, to make a kind of strategic intelligence (Huff, 1979) and get some information as one of the inputs in making important decisions in the near future.

For the purpose of illustration of successful interagency and interdepartmental cooperation in the public sector, led by an entity from the defence branch during the supporting provided to the execution of some important temporary event, the following information is given. The findings about preparations for security support of Winter Olympic Games 2010 in Vancouver (Zekulin, 2009), suggest that inter-agency cooperation is a multi-aspect challenge with more and more problems on the horizon as the number of parties involved grows. It was a large scale event, unique in nature and time dynamics, but very demanding. Interdepartmental and interagency cooperation was promoted (and ordered) by the top level strategic decision makers at the national level. All public services (including the city and regional authorities and services, various agencies, police and the military) were obligated to find ways for effective and efficient communication, cooperation, sharing resources, and overcoming any difficulties caused by different procedures, norms, organizational cultures, habits, etc. Additionally, all of them had to be available and open-minded to work together with a large number of volunteers, who were also an important supporting component in a successful organization of the Games.

Even in case of cooperation among "similar" entities (such as the military, police, security agencies), there are good opportunities for the development and elaboration of procedures for cooperation and experience exchange. Other research (Barr, 2004) explained in detail a close cooperation in the field among military and other organizations that were tasked to secure one high level international political meeting. One of the conclusions was that such a kind of inter-organizational, task-based cooperation should be expected more and more in the future. Also, findings about problems arising from inter-organizational differences in command and control philosophies are similar in both research works. 
The phenomenon of temporary working groups is also interesting from the point of view of organizational science. As a matter of fact, working groups are formed when an existing organization cannot cope with some problem on the regular basis. The following section deals with the main characteristics of the problem solving approach through engagement of Interdepartmental working groups. The third section presents an earlier example related to defence reform activities in the previous decade when more than a dozen of Interdepartmental working groups were engaged in the analysis and proposal making for a number of important subjects in defence reform. The fourth section is dedicated to a detailed exploration of one smaller but novel case related to the task of identifying the level of propensity of the population to join the Active Reserve - a new and ongoing concept of temporary military service not only in Serbia, but in many other countries who terminated military conscription system recently (Szvircsev, 2014).

\section{Some Aspects and Characteristics of Interdepartmental Working Groups}

The question of the best organizational design, or at least the most appropriate one, is relatively old (Galbraith, 1971). Unlike organizations in the field of market economy, organizational entities in the defence sector have limited possibilities to change themselves for at least one basic reason: a rigid administrative hierarchy. Instead of complete organizational reengineering, Interdepartmental working groups (IDWG) are used as an alternative way as improvement and supplement of the existing working procedures. In that sense, the IDWG in the defence sector are "invented" in order to support, accelerate and enhance regular interdepartmental cooperation.

Galbraith (1971) has pointed out two things which are crucial for an "effective coordination" among members of inter-organizational working groups: "authority" and "information" (Galbraith, 1971). According to the authors' experience with IDWG in the defence sector, the main challenge for IDWG was to find the right balance between the two mentioned components. Different departments gave different levels of authorization to their representatives. Also, departmental representatives in the IDWG usually bring different levels of knowledge and experience (or "information" according to Galbraith, 1971).

A cooperative approach opens up some specific questions related to the mutual relations of participating in organizational entities. In addition to cooperation among departments, at the same time, they can compete with each other. This paradoxical situation of parallel existence of cooperation and competition is known as "co-opetition". This term was proposed by Branderburger and Nalebuff (1995) with a basic idea of keeping in mind both aspects: cooperation and competition, in analysing inter-organizational relations. This approach is valuable and used even in contemporary analysis of internal "co-opetition" in modern companies (Song et al., 2016).

We found that "co-opetition" approach could be useful for the analysis and understanding of interdepartmental relations in the defence sector as well. Interdepartmental working groups in the defence sector have some characteristics in common, namely:

- Temporary framework: IDWG are usually formed for some specific and unique task which does not fall in the "business as usual" category; therefore, IDWG are intended to operate in some time window, and after that they are dismissed.

- Team orientation: a IDWG consists of more individuals that are expected to behave as team members; group decision making, ideally consensus, is preferred.

- Organizational heterogeneity: members of a IDWG come from different departments of the Ministry of Defence (MoD).

- Variety in knowledge of members of the IDWG: professional experience, background, education, age, rank may vary at a large scale.

- Diversity in organizational cultures: each department, as well as each service branch have some characteristics which make them at least slightly different.

- Differences in administrative and working procedures and norms: sometimes these are a result of objective factors, but many times they are caused by personal preferences of different "chiefs" of departments.

- Double loyalty: members of the IDWG are expected to be loyal to their new team - DWG, however, they have to remain loyal to their original departments (this is not the logical problem, unless in cases where the interests of IDWG and original departments are different); many of potential 
problems which may appear here, could be managed successfully with careful communication and skillful negotiations between the IDWG and corresponding departments.

- Group composition principle: very often the principle is "Representation" (it is the case when original department assigns their representative to enter a IDWG, with the main goal to formally satisfy the obligation to participate in IDWG. The second principle is "Delegation", a case when the original department gives one senior official with higher mandate with the main intention to plead for original department. The third one is "Sharing", which is the case when the original department share their resources, knowledge and people to meet the needs of IDWG. Essentially, this is a question of proper (or preferred) balancing of the "authority \& information" aspect (Galbraith, 1971).

- Mandate issues. Besides the existing departmental organizations, all of which already have prescribed responsibilities and authorizations, the problem arises when some IDWG appears and interferes across areas that are already shared among the existing stakeholders.

A detailed discussion of characteristics of the Interdepartmental working groups presented through the tabular scheme of the SWOT analysis (Strengths, Weakness, Opportunity, Threats) can be found in Nikolić et al. (2015). An imperative need for the creation of new organizational forms was pointed out by Miles et al. (2010). They said that both market companies and national states have to try and find innovative organizational forms if they want to stay at their positions and increase wealth. They point out a number of keystones towards the possible future of organizations in the 21st century, which are the following: Innovative Change, Collaboration and Networking. The need for the Innovative Change came from the stance that classical organizational designs will not be capable enough of consuming contemporary challenges as well as opportunities, at least in regard to a desired efficiency and effectiveness, available resources and other limitations. There are some terms that are well known in the context of organizational changes in the defence sector: Transformations, Reform, Transition, etc. This time, however, the centre of gravity of the organizational transformations is on the „Innovative“. Also, organizational units will have to permanently communicate (organizationally, technically, culturally) with a large number of other organizational entities of different kinds, sizes, cultures, interests, etc. It is worth mentioning that a novel research about "team resilience": Alliger et al. (2015) points out challenges which require team resilience, and finds that the role of teams will continue to grow.

\section{Interdepartmental Cooperation in Defence Sector Reform}

Modern military organizations, and defence sector as a whole, are subject of frequent initiatives for large scale reforms. This is interesting not only in transitional societies, but in many other countries too, including the most developed democracies in the West. The public sector reform is always a sensitive issue and a very complex endeavour due to many different aspects: economic, social, political, psychological, technical, organizational. Experiences and lessons learned from defence sector reforms and military transformations (around the globe, and domestic as well) could be useful at some level for other public sector branches.

Military transformations or defence reforms are often used as synonyms for marking such undertaken in the part of public administration related to the ministry of defence and armed forces. In Serbia, we have already had a few waves of reforms during the last decades. One of them was in 2006, when the "Defence Reform Group Serbia-NATO" (DRG Serbia-NATO) was created. The main goals of the DRG were declared to be the following: supporting and accelerating reforms in the defence sector; encouraging interdepartmental communication and cooperation; promoting project-oriented approach in reforms; effective use of foreign experiences and preparing participation in a special kind of cooperative program known under the name: "Partnership for Peace", etc. The DRG's structure was complex and layered, with international and political leaders at the top of the group structure. At the lower level there were numerous specialized interdepartmental working groups marked as: "Working Tables" (WT).

Overall, 16 different Working Tables were established. All groups were composed of representatives from different departments and agencies. The compositional variety was additionally enlarged by a variety of ranks, experiences, titles and ages of participating individuals. Those were interdepartmental working groups, as follows: WT-1-"Development of procedures for defence cost and analysis"; WT-2-“Development of the system for human resource management"; WT-3-"Reform of military education system"; WT-4-"Development of public relation strategy"; WT-5-“Military bases conversion”; WT-6-“Drafting a Presentation document for PFP”; WT- 
7-"Development of the system for effective and efficient defence planning"; WT-8-"Making a project of military professionalization"; WT-9-"Development of civil-military cooperation"; WT-10-"Development of a model for housing issues"; WT-11-"Conversion of military material"; WT-12-"Development of mid-term and long-term equipping plans"; "WT-13-“Democratic control and reform of intelligence and security system"; WT-14-"Reform of the military training system"; WT-15-"Development of command and communication systems"; WT-16"Development of a system for emergency management" (ISAC Fund, 2006).

Evidently, the above mentioned working groups (originally "tables") were different by name and main topic, and dealt with a very broad scope of issues and problems. Accomplishments across groups were different, but the lowest common denominator was the same: methodological approach to the problem. All groups were interdepartmental, formed on a temporary basis, worked in parallel and produced some reports and offered these to higher authorities. No doubt that some positive moves were done. Working groups made at least more informed decisions at the strategic level. Also, the DRG contributed to the exchange of ideas, information and experience among different departments. In general, groups used to operate in a relaxed way, which is immanent to the horizontal levels of hierarchy.

Beyond the DRG type of working groups, there are other ad-hock working teams created to consider other issues, such as: emergency situation coordination, proposing drafts for new normative and strategic documents, international cooperation in specific fields (European integration, PFP-Partnership for Peace program, education, etc), organizational development, standardization, terminology unification, normative framework for defence science, etc. As military reforms and transformations are almost a constant in many countries, the research efforts are always actual (Clarke, 2013) and similar modes of engagement are possible in the future. Due to the specificity of the defence and the military issues compared to other public services, there is a lot of space for international exchange related to the experience concerning organizational transformation. Many problems of the military organizations from different countries are similar and it can be useful to analyze lessons learned from others.

\section{IDWG in Strategic Intelligence on Propensity to Serve}

A proximate motivation for this paper was the experience gained from the engagement in one novel problem in the domain of interdepartmental cooperation in the Ministry of Defence. A number of departments were tasked to find solutions to a set of issues related to the implementation of the concept known as "Active Reserve“, AR. The Active Reserve (Karanović, 2011; Petrović, 2007), in the domestic context, assumes trained reserve component of the armed forces that could be engaged for manning military units for a predefined limited period. Citizens who are in AR status are in a higher level of readiness in order to be engaged when it is needed. The relationship between the individual citizen who wants to belong to the Active Reserve pool and the state (that is, military organization ) is regulated by contract.

In general, the main purpose of establishing the Active Reserve concept is to maintain a required level of operational and functional readiness of military units, staffs and defence organizations under the Ministry of Defence. Similar concepts of recruitment already exist in some other countries (MoD UK, 2012). It is supposed to be at a lower cost than holding permanently employed professional soldiers, but it still opens some questions concerning financial sustainability (Alock et al., 2014). Citizens who enter the status of AR pool, are expected to be invited for the training exercises and check-ups more frequently in comparison with all other people in the common reserve pool. In turn, they get some financial benefits for their higher readiness to serve. The importance of military reserve forces and the Active Reserve component particularly, grows with the process of professionalization of the military service and cancelling of the conscripts system in many European states (Sedivy, 2013). Active Reserve issues are subject of research and experience exchange (Keene, 2015), particularly in those states that rely more their reserve forces (Catignani, 2004).

One of the most important aspects of the Active Reserve concept is its recruitment principle. Namely, AR is completely based on a voluntary principle. This fact involves a stochastic character in AR planning. Consequently, some kind of empirical research was needed to indicate level of propensity to serve in the Active Reserve. The described constellation of influential factors was the most probable reason for the top decision level at the Ministry of Defence to place a demand for this kind of strategic intelligence. We used the term Strategic Intelligence here in the same sense as some earlier research in the field of the 
organizational sciences (as in Huff, 1979), and not as it can be possibly understood in the military or intelligence service contexts. The task had to be done in a very short time, with limited resources, in parallel with current and regular tasks, and with unresolved questions related mainly to the issues of personal data protection, approval to access and interview a wider population, as well as other issues (Nikolić et al., 2015). Quick, efficient and effective response was needed, and a solution was found in the interdepartmental approach as a way of sharing and complementing resources, capabilities and knowledge among suborganizations that are inherent parts of a larger complex organization. A schematic idea of interdepartmental cooperation with tasks and responsibilities of each organizational entity is presented in Table 1.

Table 1: Interdepartmental share of tasks and responsibilities

\begin{tabular}{|c|c|c|c|c|c|}
\hline \multirow[t]{2}{*}{ Organization } & \multirow{2}{*}{$\begin{array}{l}\text { Department } \\
\text { For Human } \\
\text { Resources } \\
\text { /Section for } \\
\text { Military Duty } \\
\text { (Recruitment) }\end{array}$} & \multirow{2}{*}{$\begin{array}{l}\text { Defence } \\
\text { Policy } \\
\text { Sector } \\
\text { /Strategic } \\
\text { Research } \\
\text { Institute }\end{array}$} & \multicolumn{2}{|c|}{$\begin{array}{l}\text { Department for Public } \\
\text { Relations }\end{array}$} & \multirow{2}{*}{$\begin{array}{l}\text { Department } \\
\text { for Strategic } \\
\text { Planning } \\
\text { /Section for } \\
\text { scientific } \\
\text { issues }\end{array}$} \\
\hline & & & $\begin{array}{l}\text { Section for } \\
\text { Informatics } \\
\text { support }\end{array}$ & $\begin{array}{l}\text { Section } \\
\text { for Public } \\
\text { Relations }\end{array}$ & \\
\hline Problem definition & $\mathrm{x}$ & & & & \\
\hline Problem structuring & $x$ & $x$ & & & \\
\hline Content/Subject analysis & $x$ & $x$ & & & \\
\hline Questionnaire formulation & & $\mathrm{x}$ & & & \\
\hline Questionnaire verification & $\mathrm{x}$ & $\mathrm{x}$ & $\mathrm{x}$ & $\mathrm{x}$ & $\mathrm{x}$ \\
\hline Questionnaire posting at website & & $\mathrm{x}$ & $\mathrm{x}$ & & \\
\hline Informing the public & & $x$ & & $\mathrm{x}$ & \\
\hline Gathering data & & $x$ & $\mathrm{x}$ & & \\
\hline Data Analysis & & $\mathrm{x}$ & & & \\
\hline Report to DM & $\mathrm{x}$ & $x$ & & & \\
\hline Scientific reports & & $x$ & & & $x$ \\
\hline
\end{tabular}

At the very beginning, Section for the Military Duties (recruitment issues) from the Department for human resources of the MoD was very specific and clear in defining their requirements, deadlines and expectations. Two main requirements were clearly emphasized and that resulted in placing two direct questions in the Questionnaire related to the level of interest to join the AR as well as the level of interest to participate in the peace missions abroad. Other elements of the Questionnaire were developed on the basis of a broader consultation, expert talks and an in-depth review of the relevant literature on the similar topics. The final version of the Questionnaire was sent to all departments and decision makers for final verification. After some improvement and corrections, the final verified version of the Questionnaire was posted at the MoD's website (MoD RS, 2014).

We have succeeded in completing the preparation and realization of empirical research in a dozen of military units and garrisons in a short time thanks to efficient engagement of an interdepartmental working group, as well as thanks to a good will of all departments included in this endeavour. Interdepartmental cooperation was particularly effective in defining the goals and scope of research, creation of the questionnaire, conducting field research in more military garrisons and regions, implementation of the electronic version of the questionnaire at the Ministry of Defence website, and informative promotion of Active reserve issues at different media. It is worth mentioning that we tried to keep all "cooperative" correspondence and activities as simple, short and concrete as it was possible. In the end we realized that all activities have been finished smoothly, and that it was a consequence of good cooperation with other departments. Hence this research effort was an initiator of new research ideas oriented towards the phenomenon of interdepartmental working groups in general, while previous experience from DRG engagement was useful as well.

\subsection{Results of Propensity Probing}

Finally, essential information about the product of this interdepartmental effort are: in less than two months (November and December 2014 collected were 708 usable responses to the questionnaire which was posted at the MoD's website (MoD RS, 2014). It was a relatively good sample size for the analysis on propensity and motivation of the population to join a specific military service in Active Reserve on contractual basis. The response was dominantly a result of intensive and professional media activities and marketing support 
performed in a synchronized manner with posting the questionnaire at the Internet site. The Department for the Public Relations of the MoD did a very good job in informing the public about a new concept of Active Reserve and in promoting ongoing research about the propensity to serve. This case confirms some earlier findings about the importance of the public relations for the military (Soldatović, 2013). The Informatics Section of the MoD has obtained software implementation of the questionnaire, as well as the electronic data collection. The contents and the structure of the questionnaire were generated in a cooperative and iterative effort among military, psychology and informatics experts from the Strategic Research Institute, as well as through the exchange of ideas with other experienced military officers and other employees across the MoD. Also, the process of the Questionnaire creation has been strongly influenced by similar research in some foreign armed forces. Particularly useful were the results offered by Steinberg (1991), and Wiggins et al. (2014).

General findings from the conducted empirical research based on the electronic questionnaire were in favour of the Active Reserve. Data showed that many of the respondents were very motivated to join the AR (Nikolić, 2015 Oct.). It was interesting that top motives to join the AR were (in this order): patriotism, earning new knowledge, gaining new qualifications, and then money as the motive - which was a little surprising. This result was different from the corresponding results from research in some other European states (Szvircsev, 2008; Taylor et al, 2015). One of very interesting findings was participation of quite a large number of female contributors: about $12 \%$ of the respondents were women. This level of interested female population for military service even outreach results from similar research conducted in much more developed countries with remarkable achievements in the field of gender issues in the military. Also, there are other results related to educational and vocational structure, age, employment, etc. (Nikolić and Zivković, 2015). In spring 2015, the Serbian MoD announced a public call to recruit candidates for a hundred positions in the Active Reserve in different units and garrisons (MoD RS, 2015).

The lessons learned in accomplishing this research task generally agree with findings in some other domestic research (Petković and Lazarević, 2012), particularly when considering an alternative approach, that is, using the outsourcing approach instead of sharing the existing capacities of a large organization as is the MoD. As a matter of fact, in case of outsourcing the research, even more people would be engaged: experts in law and finances would be needed to formulate, conduct and finalise the contract with some external research organization. At the same time, the military would have to have and engage a number experts to formulate and specify the research task as well as to track research execution and acceptance of final research report, while holding predefined standards specific for the military organization.

Conslusion

The need for interdepartmental and interagency joint endeavour emerges in cases of specific, unordinary, occasional and usually complex tasks that have to be performed. In such cases, resources, knowledge or even authorization of a single department are not enough. Hence different organizations have to work together, share resources and knowledge, coordinate plans and actions, and in general behave in a cooperative manner. In order to achieve that, different organizations delegate their members into joint working teams that are defined here as the Interdepartmental working groups. In some sense, these are a kind of parallel organizational entities. Current security, economic, social, international and other challenges, in parallel with restrictive resources, ditect different organizations, and increasingly so, towards exploiting the benefits of cooperation and joint working as well as towards decreasing mutual animosity and self-sufficiency. When things go smoothly, synergism is main gain, and interdepartmental cooperation appears as force multiplier. However, there are some potential obstacles as well.

We have tried to identify the main characteristics of the phenomenon of interdepartmental working groups in defence and security issues. The SWOT approach combined with the idea of "co-opetition" in case of interdepartmental working groups are a favourable starting point for the future research efforts in more directions, such as: definition and selection of work goals, work procedures specifications, mandate definition, responsibilities, deliveries, team members selection, participating departments selection, selection of group decision making methods, consensus reaching methods, measuring achievements, identifying obstacles, clearing up relations with existing hierarchies, etc. 
The paper presents two examples of IDWGs in the defence branch. The former is a case of a specific approach towards considering strategic questions of defence reform. The latter is a novel example from the field of strategic intelligence, when some important questions related to the military recruitment had to be resolved in a very short time, with very scarce resources and encompassing a very broad population. Probing propensity of population to serve in the Active Reserve was a novel example from the field of strategic intelligence in the defence sector. It confirmed benefits of interdepartmental cooperation. In short, the Research Institute was tasked to perform a kind of strategic intelligence on the issues related to the propensity and motivation of a wider population in regard to specific and temporary military service known as the Active Reserve. In a very short time it needed to inform the public about new recruitment concept, inform and attract the public to participate in questionnaire fulfilment, create appropriate questionnaire, investigate other countries' experiences on the topic, collect data, prepare and analyse gathered data, and finally to prepare a technical report to the decision makers who actually initiated this strategic intelligence. A successful completion of the task assumes a high level of productive cooperation among: research department, public relation department, informatics section, marketing section, department for human resources and recruitment, as well as other departments interested in the topic.

\section{REFERENCES}

[1] Alliger, G., Cerasoli, C., Tannenbaum, S., Vessey, W. (2015). Team Resilience: How Teams Flourish Under Pressure. Organizational Dynamic, 44, 176-184. doi: 10.1016/j.orgdyn.2015.05.003.

[2] Alock, S., Greenhalgh, K., Taylor, L., Murphy, P. (2014). Who Pays for Gareth? Relyung on Reservists: The UK Government's Strategic Defence and Security Review. The Journal of Finance and Management in Public Services, 14(1), Retrieved from: http://www.cipfa.org/policy-and-guidance/the-journal-offinance-and-management-in-public-services

[3] Barr, D. (2003-2004, Winter). The Kananskis G8 Summit: A Case Study in Interagency Cooperation. Canadian Military Journal, 39-46.

[4] Borgatti, S., Foster, P. (2003). The Network Paradigm in Organizational Research: A Review and Typology. Journal of Management, 29(6), 991-1013.

[5] Brandenbauer, A., Nalebuff, B. (1995). The Right Game: Use Game Theory to Shape Strategy. Harvard Business Review, 73(4), 57-71.

[6] Catignani, S. (2004). Israeli Defence Forces Organizational Changes in an Era of Budgetary Cutbacks. RUSI Journal, 149(5), 72-76.

[7] Clarke, J. (2013). Europe's Armed Forces in Civil Security. Connections: The Quarterly Journal, 12(2), 69-82. Retrieved from: http://dx.doi.org/10.11610/ Connections.12.2.04.

[8] Čudanov, M., JaŠko, O., JevtiĆ, M. (2009). Influence of Information and Communication Technologies on Decentralization of Organizational Structure. ComSIS, 6(1), 93-109. doi: 10.2298/CSIS0901093C

[9] Čudanov, M., Jaško, O., Savoiu, G. (2010). Interrelationships of Organization Size and Information and Communication Technology Adoption. Journal of Applied Quantitative Methods, 5(1), 29-40.

[10] Eisenhardt, K., Galunic, C. (2000). Coevolving At Last, a Way to Make Synergies Work. Harvard Business Review, 84(9), 91-101.

[11] Galbraith, J. (1971). Matrix Organization Designs. Business Horizons, 14(1), 29-40.

[12] Hakansson, H., Snehota, I. (1995). Developing Relationships in Business Networks. Routledge, London. ISBN 0-415-11570-1.

[13] Huff, A. (1979). Strategic Intelligence Systems. Information \& Management, 2, 187-196.

[14] ISAC fond. (2006). Vodic kroz parterstvo za mir.

[15] Jaško, O., Jaško, A., Čudanov, M. (2010). Uticaj upravljanja na efikasnost organizacione mreze. Proceedings, XXII International Symposium SymOrg-2010, Zlatibor, Serbia, 5-12.

[16] Karanović, N. (December 01, 2011). Aktivna i pasivna rezerva. Odbrana, special appendix of the magazine No.71, Media Center Odbrana, Beograd.

[17] Keene, S. (2015). The Effective Use of Reserve Personnel in the U.S. Military: Lessons from the United Kingdom Reserve Model. Report, Strategic Studies Institute and U.S. Army War College Press. Retrieved from: www.strategicstudiesinstitute.army.mil/ pubs/display.cfm?pubID=1245

[18] Miles, R., Snow, C. (1986). Organizations: New Concepts for New Forms. California Management Review, XXVIII(3), 62-73.

[19] Miles, R., Snow, C. (1995). The New Network Firm: A Spherical Structure Built on a Human Investment Philosophy. Organizational Dynamic, 23(4), 5-18. 
[20] Miles, R., Snow, C., Fjeldstad, O., Miles, G., Lettl, C. (2010). Designing Organizations to Meet $21^{\text {st }}$ Century Opportunities and Challenges. Organizational Dynamic, 39(2), 93-103. doi: 10.1016/j.orgdyn.2010.01.009

[21] Ministry of Defence RS. (2014). Questionnaire about propensity and motivation to serve in the Active Reserve. Retrieved from: .

[22] Ministry of Defence RS. (2015). Public Call for the Active Reserve, Retrieved from: .

[23] Ministry of Defence, the United Kingdom. (2012, November). Future Reserves 2020: Delivering the Nation's Security Together. A consultation paper presented to Parliament by Secretary of State for Defence. Retrieved from:

[24] Nikolić, N., Živković, U. (2015, June). Reserve Recruitment Pool Vocational Structure - Reference for Military Unit Life Cycle Efficiency. Proceedings, 6th International Conference "Life Cycle Engineering and Management", IC DQM 2015, Prijevor, Serbia, 291-297.

[25] Nikolić, N. (2015, October). Serbian Security Perceptions: Motivations to Serve. Information \& Security: An International Journal, 33(2), 122-137. , ().

[26] Nikolić, N., Janković, S., Vuletić, D. (2015, November). Interdepartmental Working Groups in Support of Strategic Intelligence. Proceedings, X Symposium of Business and Science SPIN'15, Belgrade, Serbia, 409-415.

[27] Petković, M., Aleksić-Mirić, A. (2009). Managing Organizational Knowledge While Downsizing Organizations. Tourism and Hospitality Management 15(2), 257-265.

[28] Petković, M., Lazarević, S. (2012). Managing Interorganizational Relations: Design of Shared Services Centre. Management Journal for Theory and Practice Management, 64, 55-67. doi: 10.7595/management.fon.2012.0024

[29] Petković, M., Aleksić-Mirić, A., Čudanov, M. (2014). Designing a Learning Network Organization. Management Journal for Theory and Practice Management, 73, 17-24. doi: 10.7595/management.fon.2014.0029.

[30] Petrović, Z. (2007). Ratna vojska Srbije u uslovima potpune profesionalizacije. Vojno Delo, 59(4), 108130. ISSN 0042-8426.

[31] Sedivy, J. (2013). NATO and Reserve Forces - a Czech View. The Officer, 2013, Retrieved from: index_2.html

[32] Snow, C., Miles, R., Coleman, H. (1992). Managing $21^{\text {st }}$ Century Network Organizations. Organizational Dynamic, 20(3), 5-20.

[33] Soldatović, I. (2013). PR Impact on Public Confidence in Military and Police in Serbia. Management Journal for Theory and Practice Management, 67, 77-83. doi: 10.7595/management.fon.2013.0007

[34] Song, J., Lee, K., Khanna, T. (2016). Dynamic Capabilities at Samsung: Optimizing Internal Co-opetition. California Management Review, 58(4), 118-140.

[35] Steinberg, A. (1991). Individual Ready Reserve (IRR) Call-Up: Attitudes, Motivations, and Concerns. Research Report 1594, US Army Research Institute.

[36] Szvircsev, T. (2014, 3-4 December). Europe's Armed Forces in Transition: From Conscription to allvolunteer forces 1975-2014. International Workshop "10 Years after Suspending Conscription: Transition and Transformation".

[37] Szvircsev, T. (2008). Challenges in the Recruitment of Professional Soldiers in Europe. Strategic Impact, 3. $76-86$.

[38] Taylor, J., Clerkin, R., Ngaruiya, K., and Knox Velez, A.L. (2015). An Exploratory Study of Public Service Motivation and the Institutional-Occupational Model of the Military. Armed Forces \& Society, 41(1), 14262. Retrieved from: //dx.doi.org.10.1177/0095327X13489119

[39] Zekulin, M. (2009). Olympic Security: Assessing the Risk of Terrorism at the 2010 Vancouver Winter Games. Journal of Military and Strategic Studies, 12(1), 2-25.

[40] Wiggins, B., Evans, S., Luchman, J., Gibson J. (2014). Motivators and Barriers to Recruiting Prior Service Members in the IRR. Military Psychology, 26(1), 23-32. //dx.doi.org/10.1037/mil0000026

Acknowledgement. This work is supported in part by the Ministry of Education, Science and Technological Development, Republic of Serbia, under Project No.III-47029. 


\title{
$1 / 1 / 1 / 1 / 1 / 1 / 1 / 1 / 1 / 1 / 1 / 1 / 1 / 1 / 1 / 1 /$ abouthe euthor
}

\author{
Nebojsa Nikolic \\ Strategic Research Institute, Ministry of Defence \\ Corresponding author: nebojsa2008_g@yahoo.com
}

Nebojsa Nikolic (1964), PhD, is a research associate at the Strategic Research Institute and associate professor at the Military Academy. Prior to academic work he performed numerous duties in military units. His research interest is highly influenced by the needs

of the military organization and oriented towards: decision making theory, strategic management, multi-criteria ranking problems, simulation, logistics and other disciplines relevant to the military organizations.

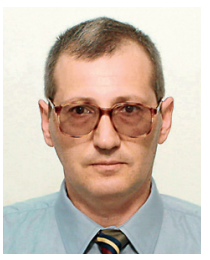

Svetlana Jankovic Strategic Research Institute, Ministry of Defence

Svetlana Jankovic, MA, is a research assistant at the Strategic Research Institute. She is a Lieutenant Colonel of the Serbian Army with a strong professional background acquired on numerous duties in different military units and commands across the country. She earned her master's degree at the Faculty of Civil Defense in Belgrade. Her areas of expertise are defence and security, gender and resources protection.

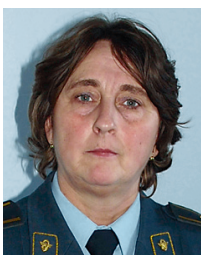

\section{Dejan Vuletic \\ Strategic Research Institute, Ministry of Defence}

Dejan Vuletic (1972), PhD, is a Lieutenant Colonel and a member of the Strategic Research Institute since 2004. He graduated in 1995, defended his Master thesis in 2005 at the Military Academy, and his PhD thesis: "Cyber Crime and the possibility of its detection" in 2009 at the Faculty of Organizational Sciences in Belgrade. He is an assistant professor at the Military Academy, in the informatics area. 